\title{
Clinical features of diabetic patients with dry eye disease in a community in Maceio: a cross-sectional study
}

\section{Características clínicas de pacientes diabéticos com olho seco em uma comunidade de Maceió: estudo transversal}

Marina Viegas Moura Rezende Ribeiroํ, Fabiano Timbó Barbosa², Luiz Eduardo Feliciano Ribeiro ${ }^{3}$, Celina Maria Costa Lacet ${ }^{4}$, João Marcelo de Almeida Gusmão Lyra ${ }^{4}$, Êurica Adélia Nogueira Ribeiro²

\begin{abstract}
Objective: This study was carried out in order to assess the epidemiological profile of symptomatic dry eye in diabetic patients. Methods: Two hundred and twenty-one diabetic patients were evaluated using a specific questionnaire about other diseases and drugs. Of these, 58 who classified as having moderate to severe dry eye were included. Results: In this study, 58 of the 221 diabetic patients had moderate to severe dry eye (26.2\%). Of the 58 patients, dry eye was more prevalent at age $61.46 \pm 14.18$ years for men, and $61.09 \pm 10.64$ for women $(p<0.005)$. Dry eye was more common in women $(75.9 \%)(p=0.456)$. Of the 58 patients, $15(25.9 \%)$ had at least one ocular disease. The most common was diabetic retinopathy (13 of 15 patients, $86.7 \%, 95 \%$ CI 69.46-103.87). A total of 19 patients used eye drops (32.8\%); and most (14 of the 19 individuals, 73.7\%) used lubricants (95\% CI 53.88-93.48). Hypertension was the most prevalent associated comorbidity $(56.9 \%)$ and the most commonly used medications were hypoglycemic agents (98 \%, 95\% CI 94.00 - 101.92) and angiotensin converting enzyme inhibitors $(53.1 \%, 95 \%$ CI 53.0639 .09 - 67.04). Conclusion: Further epidemiologic studies need to be done to establish a real etiologic relationship between diabetes and dry eye, and its correlation to other risk factors. In spite of these limitations, we have strong evidence of this relationship, and in clinical practice, examination for dry eye should be part of the assessment of diabetic disease.
\end{abstract}

Keywords: Dry eye/epidemiology; Diabetes mellitus/complications, critical patient, epidemiology, profile

\section{ReSUMO}

Objetivo: O estudo foi realizado para descrever o perfil epidemiológico de pacientes diabéticos com olho seco sintomático. Métodos: Duzentos e vinte e um pacientes diabéticos foram avaliados por meio de questionário específico sobre outras doenças e medicamentos. Destes, 58 foram diagnosticados com olho seco moderado a severo e foram incluídos no estudo. Resultados: Neste estudo, 58 dos 221 pacientes diabéticos tinham olho seco moderado a severo $(26,2 \%)$. Dos 58 pacientes, o olho seco, foi mais prevalente na faixa etária de $61,46 \pm 14,18$ anos para os homens e $61,09 \pm 10,64$ para as mulheres ( $\mathrm{p}<0,005)$. O olho seco foi mais comum em mulheres $(75,86 \%)(\mathrm{p}=0,456)$. Dos 58 pacientes, $15(25,9 \%)$ tinham pelo menos uma doença ocular. A mais comum foi a retinopatia diabética (13 de 15 pacientes, $86,7 \%$, IC de $95 \%$ 69,46-103,87). Um total de 19 pacientes utilizavam colírios (3,8\%); lubrificantes foram os mais usados (14 dos 19 indivíduos, 73, 7\%, (IC de 95\%, 53,88-93,48). A hipertensão foi a doença mais prevalente associada (56.9\%) e os medicamentos mais utilizados foram hipoglicemiantes orais $(98 \%$, IC $95 \% 94,00-10,92)$ e inibidores da enzima conversoras da angiotensina (53,1\%, IC 95\%, 53,06 39,09-67,04). Conclusão: Novos estudos epidemiológicos devem ser feitos para avaliar a real relação etiológica entre olho seco e diabetes e sua correlação com outros fatores de risco. Apesar das limitações, temos fortes evidências da relação entre olho seco e diabetes. Na prática clínica, o exame de olho seco deve ser parte da avaliação dos diabéticos.

Descritores: Olho seco/epidemiologia; Diabetes Melittus/complicações

\footnotetext{
${ }^{1}$ Programa de Pós-graduação em Ciências da Saúde, Universidade Federal de Alagoas, Maceió, AL, Brasil. Brasil.

${ }^{2}$ Universidade Federal de Alagoas, Maceió, AL, Brasil.

${ }^{3}$ Instituto de Olhos de Maceió, Maceió, AL, Brasil.

${ }^{4}$ Universidade de Ciências da Saúde de Alagoas, Maceió, AL, Brasil.
}

The authors declare no conflicts of interests.

Received for publication 23/10/2015 - Accepted for publication 12/01/2016 


\section{INTRODUCTION}

D iabetes Mellitus is a disease which is often followed by microvascular complications, such as nephropathy, neuropathy and retinopathy. ${ }^{(1)}$ It is one of the main causes of blindness in people aged between 20 and 74. (2)

Dry eye disease (DES) is a major tear deficiency disorder which causes discomfort, visual disturbances and tear film instability with potential damage to the ocular surface. ${ }^{(3)}$ Dry eye can lead to vision deficit, scarring, cornea perforation, and secondary bacterial infection. It is important, then, to make early diagnoses of this disease. ${ }^{(4)}$

Reported prevalence of dry eye is diverse, with questionnairebased surveys documenting rates ranging from $14.4 \%$ to $33 \%$ of the population. ${ }^{(5-8)}$ Studies which also involve tests of tear function for determination of dry eye, including Schirmer's test, tear break up time and others, have generally found lower prevalence rates. ${ }^{(8)}$ However, there have been discrepancies in the prevalence reported in the literature, due to a lack of consensus about appropriate diagnostic criteria and differences in the parameters and research methodology applied. ${ }^{(9)}$

Generally, diabetic patients have classic symptoms of dry eye, including irritation, foreign body sensation, burning, itchiness, pain or redness; they usually also have alterations in Schirmer test. ${ }^{(10)}$ Autonomic dysfunction may be the mechanism responsible for dry eye in the diabetic patient, and aldose reductase, the first enzyme of the sorbitol pathway, may also be involved. ${ }^{(11)}$ Jin et al., showed that diabetic type 2 patients have a greater tendency to develop tear dysfunction. ${ }^{(12)}$ Few studies reported prevalence of dry eye in diabetic patients in the literature, and these rates ranged from between $14.4 \%$ to $54.3 \%(7 ; 12-17)$. There is a lack of studies that describes the profile of the diabetic patient with moderate to severe dry eye. We aimed, therefore, to describe the epidemiologic profile of diabetic patients with moderate to severe dry eye, and to try to evaluate the relationship with possible associated risk factors.

\section{MethodS}

In a prospective observational study, from December, 2014 to April 2015, we evaluated 221 diabetic patients that were referred to the ophthalmologic department of the Dr. Alberto Antunes University Hospital or to the João Paulo II Reference Unit, both located in the city of Maceió, Alagoas State, Brazil. These patients were diagnosed previously with diabetes according to ADA criteria. ${ }^{(2)}$

Informed consent was obtained from all subjects and the research had the approval of the institutional board and ethics committee (Universidade Federal de Alagoas) and the National Committee of Ethics and Research (CONEP: 30435114.6.0000.5013)

Clinical data of all patients included sex, age groups (35 to $45.8,45.8$ to $56.6,56.6$ to $67.4,67.4$ to $78.2,78.2$ to 89 years old), race (black, white, yellow, brown or indigenous), duration of diabetes, fasting glycaemia, history of other diseases, like heart disease, recent stroke history (less than 6 months), psychiatric or neurologic diseases or dementia, rheumatic diseases, thyroid diseases, intestinal inflammatory disease, asthma or other allergic diseases, report of dry mouth or another mucosae, ocular diseases (cataract, glaucoma, macular degeneration, keratopathies, diabetic retinopathy), previous ocular surgeries, photocoagulation report, use of eye drops, use of medication and cigarette smoking. The data was obtained by reviewing the medical records and through direct interview of the patient.

Dry eye patients were defined in our study as individuals that had at least one of the classical symptoms plus one or more alterations in the objective tests analyzed. They were evaluated for common symptoms of dry eye ocular discomfort ${ }^{(17)}$ including: soreness, gritty sensation, itchiness, redness, blurred vision that improves with blinking and excessive tearing. The frequency of these symptoms was graded as: never (graded as "1"), rarely (at least once in 3-4 months, graded as "2"), often (at least once a week, graded as " 3 ") or all the time (graded as "4"). These patients were then submitted to a Schirmer test. The Schirmer test was graded as follows: " 1 ", when it was $15 \mathrm{~mm}$ or more in 5 minutes; " 2 ", when it was less than $15 \mathrm{~mm}$; " 3 " when it was less than $5 \mathrm{~mm}$; and " 4 when it was less than $2 \mathrm{~mm}$. Those that reported one or more of the symptoms graded as " 3 " or " 4 " and had a Schirmer test inferior to $15 \mathrm{~mm}$ in 5 minutes ${ }^{(17)}$ were defined as having moderate to severe dry eye, based on criteria proposed by the American Academy of Ophthalmology ${ }^{(18)}$ and DEWS. ${ }^{(19)}$

Corrected visual acuity was assessed in all patients. Structures of the eye were assessed with slit lamp biomicroscopy examination. Retinal status was evaluated by indirect ophthalmoscopy after dilation using a tropicamide $1 \%$ drop.

We also evaluated conjunctival injection, corneal staining with fluorescein, conjunctival staining, corneal or tear signs, meibomius glands and lid alterations and break-up time (BUT), as follows: ${ }^{(19)}$

Conjunctival injection: graded from " 1 " to "4", indicating absent, mild, moderate and severe signs respectively;

Conjunctival staining: graded from " 1 " to " 4 ", indicating none to mild, variable, moderate to marked, and marked respectively;

Corneal staining: graded from " 1 " to " 4 ", indicating none to mild in grade " 1 ", variable in grade " 2 ", marked central in grade " 3 ", and severe punctate erosions in grade " 4 ";

Corneal or tear signs: graduated from " 1 " to "4" which means none to mild, mild debris and reduced meniscus, mucus clumping plus filamentary keratitits and the final stage with all these signals in addition to ulceration.

Meibomius glands and lid alterations were also graded from " 1 " to "4", indicating variable to present in first two stages, frequent in third stage, and with possible symblepharon and trichiasis in the last grade.

BUT classification also followed DEWS, and means normal (1), equal or less than 10 seconds (2), equal or less than 5 seconds (3) and equal or less than 2 seconds (4), respectively. ${ }^{(19)}$

\section{Statistical methods}

Statistical analysis was performed using the Statistical Package for Social Sciences (SPSS version 20.0, Chicago IL). Significance was considered to be $\mathrm{P}<0.05$. Results were given with their $95 \%$ CIs. Data were presented as mean \pm SD Data normal distribution and verified by the Kolmogorov-Smirnof test. Age-group analysis was performed using the Kruskal-Wallis test. Gender group analysis was performed using the Mann Witney U test.

Grading of symptoms and signs, based on DEWS criteria, and American Academy of Ophthalmology, ${ }^{(18,19)}$ were presented as median and amplitude. 


\section{Results}

In this study, 221 diabetic patients were assessed. There were 58 patients $(26.2 \%)$ included in the study, which filled the criteria of moderate and severe dry eye. There were 14 men $(24.1 \%)$ and 44 women $(75.9 \%)$. The mean age of subjects was $61.46 \pm 14.18$ years for men, and $61.09 \pm 10.64$ for women. The distribution in age groups was statistically significant $(\mathrm{p}<0.005)$.

Ethnic group distribution in dry eye patients was: $19 \%$ brown, $58.6 \%$ white and $22.4 \%$ black. No patients self-declared yellow or indigenous ethnicities.

Most patients were in the 56.6 - 67.4 year-old group (43.1\%), while the 35-45.8 year-old group had the fewest (6.9\%).
Male patients $(n=14)$ with dry eye disease had a mean duration of diabetes of $11.22 \pm 9.705$ years whereas this was 9.86 \pm 8.155 years in women subjects $(n=44)$. The highest mean of diabetes duration time was found in the 67.4-78.2 year-old group $(13.29 \pm 9.57)$. Mean duration of diabetes was not statistically significant among sex and age $(\mathrm{p}=0.718$ and $\mathrm{p}=0.711$ respectively). Highest fasting glycaemia $(226 \pm 66.12)$ was verified in the 35 45.8 year old group, and was highest in men (216.62 \pm 139.462$)$. However, it was not statistically significant among age and sex $(\mathrm{p}=0.277$ and $\mathrm{p}=0.456$ respectively), (Tables 1 and 2$)$.

Ocular discomfort was defined as having one or more traditional dry eye symptoms, and all patients were graded in grade " 3 " or " 4 ". The Schirmer test was evaluated with median and amplitude and ranged from " 2 " to " 4 ", the latter found in the

Table 1

Patient profile by age group and gender - mean variables (SD)

\begin{tabular}{|c|c|c|c|c|c|c|}
\hline Age Groups & No. & Age & Glycaemia & Diabetes Duration Yrs. & VA OD & VA OS \\
\hline $35-45.8$ & 4 & $39.50(4.20)$ & $226(66.12)$ & $12(9.90) 0.6(0.4)$ & $0.87(0.231)$ & \\
\hline $45.8-5.6$ & 14 & $51.43(2.74)$ & $223.36(130.47)$ & $9.80(7.54)$ & $0.49(0.306)$ & $0.51(0.271)$ \\
\hline $56.6-67.4$ & 25 & $61.40(2.99)$ & $166.80(78.78)$ & $8.35(7.32)$ & $0.56(0.334)$ & $0.51(0.346)$ \\
\hline $67.4-78.2$ & 9 & $70.78(3.03)$ & $192.11(121.85)$ & $13.29(9.57)$ & $0.32(0.200)$ & $0.37(0.305)$ \\
\hline $78.2-89$ & 6 & $83.00(3.46)$ & $140.83(65.93)$ & $12.00(12.47)$ & $0.35(0.392)$ & $0.48(0.386)$ \\
\hline p value & & $<0.001$ & 0.277 & 0.711 & 0.256 & 0.266 \\
\hline Gender & No. & Age & Glycaemia & Diabetes Duration Yrs. & VA OD & VA OS \\
\hline Male & 14 & $61.46(14,18)$ & $216.62(139.462)$ & $11.22(9.705)$ & $0.44(0.323)$ & $0.5(0.365)$ \\
\hline Female & 44 & $61.09(10,64)$ & $176.87(85.426)$ & $9.86(8.155)$ & $0.50(0.326)$ & $0.51(0.320)$ \\
\hline p value & & 0.55 & 0.456 & 0.718 & 0.567 & 0.992 \\
\hline
\end{tabular}

Table 2

Patient profile by age group and gender; clinical signs

Median variables and amplitude

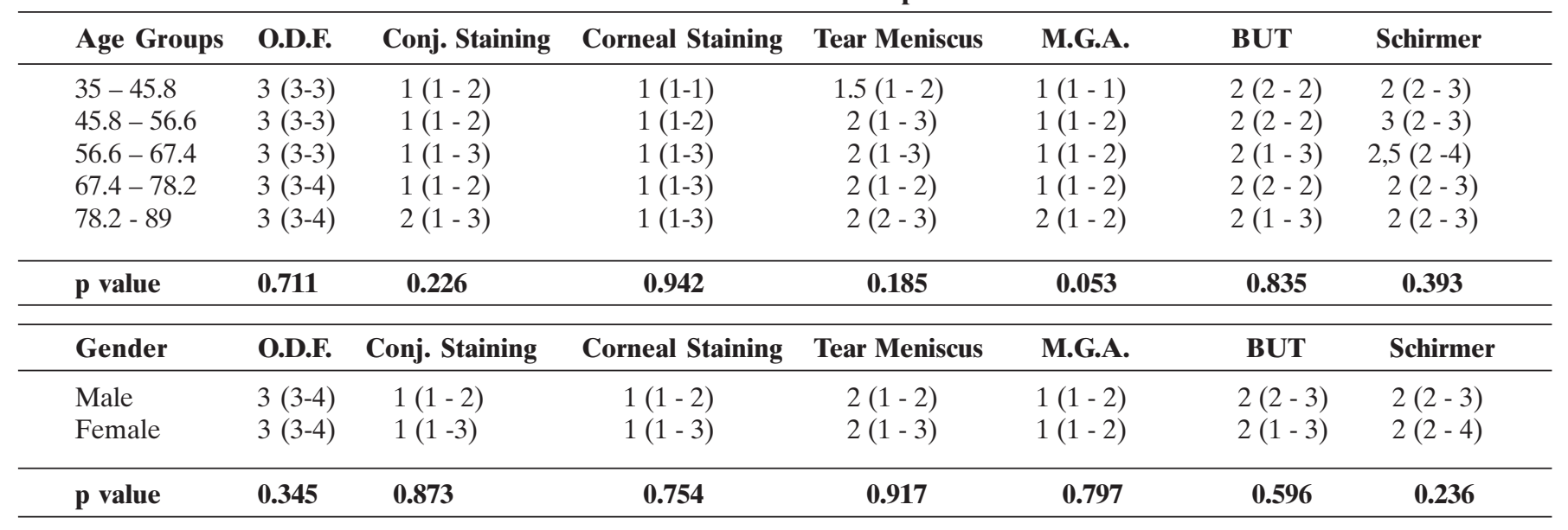

O.D.F.: Ocular Discomfort Frequency - 1: Absent 2: Mild 3: Moderate 4: Intense Conj. Staining: Conjunctival Staining - 1: Absent 2: Mild 3: Moderate 4: Intense Corneal Staining - 1: Absent 2: Mild 3: Moderate 4: Intense1: 2: 3 :

Tear Meniscus - 1: normal 2: mildly reduced 3: moderate 4: severe

M.G.A.: Meibomius Gland Alterations 1: Absent 2: Mild 3: Moderate 4: Intense

BUT: Break-up time - 1: Variable 2: $<10$ s $3:<5$ s 4 : immediate

Schirmer: 1: Variable 2: $<15 \mathrm{~mm} 3:<5 \mathrm{~mm} \mathrm{4}:<2 \mathrm{~mm}$ 
56.6-67.4 age group; there was no statistical significant difference between men and women $(\mathrm{p}=0.236)$. Results from other parameters, including conjunctival injection, corneal staining with fluorescein, conjunctival staining with fluorescein, reduced tear meniscus, meibomius gland alterations, break-up time (BUT) and visual acuity, and comparing them for age and sex, showed no statistical significance (Tables 1 and 2).

Of the 58 patients, $15(25.9 \%)$ had at least one ocular disease. The most common was diabetic retinopathy (DR) (13 of 15 patients, $86.7 \%$, 95\% CI 69.46-103.87), the least common was macular degeneration (1 of 15 patients: 6.7\% 95\% CI -5.96-19.29). Previous ocular surgery was present in 28 of the 58 patients $(48.27 \%)$.

Non-proliferative diabetic retinopathy was present in 10 patients $(17.2 \%$ of the 58 selected individuals) and the other three had a proliferative form of the condition; two of these three had been submitted to photocoagulation.

A total of 19 patients used eye drops (32.8\%); most used lubricants of various types (14 of the 19 individual, (73.7\%; $95 \%$ CI 53.88-93.48) and 8 (42.1\%; 95\% CI 19.90-64.32) of them used ocular hypotensors for glaucoma (Table 3).

Table 3

Associated ocular conditions

Ocular Diseases $(\mathrm{N}=15)$

\begin{tabular}{llll}
\hline & $\mathbf{N}$ & $\mathbf{\%}$ & $\mathbf{9 5 \%} \mathbf{~ C I}$ \\
\hline Cataract & 5 & 33.3 & $9.5-57.2$ \\
Glaucoma & 10 & 66.7 & $42.9-90.5$ \\
ARMD & 1 & 6.7 & $-6.0-19.3$ \\
Diabetic retinopathy & 13 & 86.7 & $695-103.9$ \\
\hline
\end{tabular}

Use of eye drops $(\mathrm{N}=19)$

Use of glaucoma eye drops

$8 \quad 42.1 \quad 19.9-64.3$

Use of lubricant eye drops

$14 \quad 73.7 \quad 53.9-93.5$

Associated comorbidities and use of medication were also followed (Tables 4 and 5).

Table 4

Associated systemic comorbidities $(\mathrm{N}=58)$

\begin{tabular}{|c|c|c|c|c|}
\hline & & $\mathbf{N}$ & $\%$ & $95 \% \mathrm{CI}$ \\
\hline \multirow[t]{2}{*}{ Smoking } & Yes & 2 & 3.4 & $-1.2-8.1$ \\
\hline & No & 56 & 96.6 & $91.9-101.2$ \\
\hline \multirow[t]{2}{*}{ Thyroid disease } & Yes & 6 & 10.3 & $2.5-18.2$ \\
\hline & No & 52 & 89.7 & $81.8-97.5$ \\
\hline \multirow[t]{2}{*}{ Rheumatic disease } & Yes & 9 & 15.5 & $6.2-24.8$ \\
\hline & No & 49 & 84.5 & $75.1-93.8$ \\
\hline \multirow[t]{2}{*}{ Amputation } & Yes & 2 & 3.4 & $-1.2-8.1$ \\
\hline & No & 56 & 96.6 & 91.9- 101.2 \\
\hline \multirow{2}{*}{ Psychiatric / Dementia } & Yes & 1 & 1.7 & $-1.6-5.1$ \\
\hline & No & 57 & 98.3 & $94.9-101.6$ \\
\hline \multirow[t]{2}{*}{ Dialysis } & Yes & 3 & 5.2 & $-0.5-10.9$ \\
\hline & No & 55 & 94.8 & $89.1-100.5$ \\
\hline \multirow[t]{2}{*}{ Stroke } & Yes & 3 & 5.2 & $-0.5-10.9$ \\
\hline & No & 55 & 94.8 & $89.1-100.5$ \\
\hline \multirow[t]{2}{*}{ Allergies / Bronchitis } & Yes & 3 & 5.2 & $-0.5-10.9$ \\
\hline & No & 55 & 94.8 & $89.1-100.5$ \\
\hline \multirow{2}{*}{ Arterial hypertension } & Yes & 33 & 57 & $44.1-69.6$ \\
\hline & No & 25 & 43.1 & $30.4-55.8$ \\
\hline
\end{tabular}

Table 5

Use of oral medication

$(\mathrm{N}=49)$

\begin{tabular}{lllc}
\hline & $\mathbf{N}$ & $\mathbf{\%}$ & $\mathbf{9 5 \%} \mathbf{C I}$ \\
\hline Hypoglycemic agents & 48 & 98 & $94-101.9$ \\
Insulin & 17 & 34.7 & $21.4-48$ \\
Diuretics & 19 & 38.8 & $25.1-52.4$ \\
Calcium channel blockers & 8 & 16.3 & $6-26.7$ \\
ACE Inhibitor & 26 & 53.1 & $39.1-67$ \\
Lipid lowering agent & 7 & 14.3 & $4.5-24.1$ \\
ASA & 7 & 14.3 & $4.5-24.1$ \\
Beta blocker & 8 & 16.3 & $6-26.7$ \\
Benzodiazepine & 11 & 22.4 & $10.8-34.1$ \\
Antidepressants & 8 & 16.3 & $6-26.7$ \\
Steroids & 2 & 4.1 & $-1.5-9.6$ \\
Proton pump inhibitors & 5 & 10.2 & $1.7-18.7$ \\
Digitalis & 1 & 2 & $-1.9-6$ \\
Thyroxine & 3 & 6,12 & $-0.6-12.8$ \\
\hline
\end{tabular}

*ASA: acetylsalicylic acid, *ACE: angiotensin-converting-enzyme

\section{DisCUSSION}

Several previous studies have investigated the relationship between DM and dry eye. Although some found an increased risk ${ }^{(7,15)}$, others found neither a significant decrease in aqueous tear flow nor impaired TFBUT among those treated with insulin ${ }^{(10)}$. Kaiserman ${ }^{(20)}$ verified that DM increases dry eye and its severity. Seifart et al. found a $70 \%$ rate of dry eye in type 2 diabetes ${ }^{(13)}$. Sendecka et al. reported that the most important conditions associated with dry eye were diabetes and hypertension. ${ }^{(14)}$ Jain et al. presented 80 diabetic patients in a group of 400 patients with dry eye. ${ }^{(16)}$ The cause of this correlation may be autonomic neuropathy and damage to microvasculature of the lacrimal gland, as well as sensorial corneal neuropathy. ${ }^{(11)}$

We used a questionnaire to assess the classic symptoms of dry eye, ${ }^{(18,19)}$ selecting those graded " 3 " and " 4 " and associated to the Schirmer test inferior to $15 \mathrm{~mm}$ in 5 minutes. Some studies report that Schirmer and BUT decreased in diabetic dry eye ${ }^{(10,13)}$, in contrast to other authors that found that Schirmer, BUT and rose bengal staining have low sensitivity and underestimate dry eye disease when compared with a self-reported questionnaire about symptoms ${ }^{(8,15)}$. Symptoms can be regarded as very important, due to the lack of correspondence between them and all these tests in diagnosing dry eye ${ }^{(21)}$ Clinicians in practice also rely heavily on the evaluation of symptoms for dry eye diagnosis ${ }^{(21,22)}$.

The frequency of moderate to severe dry eye in our study was $26.2 \%$ (58 patients). We did not evaluate prevalence of mild dry eye because our priority was frequent symptomatic dry eye, and mild cases usually have episodic symptoms or none at all. ${ }^{(19)}$ There are few studies of prevalence of dry eye in diabetic patients, and it ranges from between $14.4 \%{ }^{(7)}$ to $54.3 \%{ }^{(17)}$. We did not find any other study that used only moderate to severe dry eye syndrome specifically in diabetes. But we know that prevalence of dry eye in the general population also presents a variation with environmental conditions, such as sunshine exposition, which increases this rate, and a high humidity ambient, that reduces it ${ }^{(23)}$. 
In this study we found that $24.4 \%$ were men and $75.86 \%$ were women, but it was not statistically significant. Some authors $(14,15,20,21)$ found that dry eye incidence increases in women; one of the explanations is the low rate of protector hormones like androgens. Other studies in diabetics show that diabetes keratoconjunctivitis sicca has no sex predilection. ${ }^{(17,20)}$ One hypothesis for this is that some of the anatomical and physiological modifications of the meibomian gland during aging have been linked to androgen deficiency, concurring with androgenic control of sebaceous glands in the skin ${ }^{(24)}$. Therefore, this predilection is not so important with aging, because both men and women have a lower androgen pool when older.

Our research presented a mean age of moderate to severe dry eye of $61.46 \pm 14.18$ in men and $61.09 \pm 10.64$ in women, and these distributions of age groups was statistically significant. Kaiserman et al. found higher prevalence of dry eye with age in diabetics ${ }^{(20)}$, while Liu et al. found that diabetes and increased age were important risk factors to dry eye in a systematic review. ${ }^{(25)}$ However, Manaviat et al. ${ }^{(17)}$ did not find higher age to be a risk factor in diabetics with dry eye. We believe that it seems to be plausible that the dysfunction of lachrymal and meibomius glands with androgen insufficiency and other disjunctions that occur with age can contribute to an increase in dry eye disease in older people, irrespective of whether they are diabetic or not.

In our study we found a higher incidence of white people; others, however, showed no association with ethnic groups. (21) The 2010 census reported that $50.7 \%$ of the Brazilian population is black or brown, with the largest proportion of this group located in the Northeast region ${ }^{(26)}$. However, Cavalli-Sforza reports that all ethnic classification is "difficult, imperfect and arbitrary", (27) and we can attribute this to the fact that its definition ranges from one time to another and according to the reason for it to be evaluated.

Time from diagnosis of diabetes and fasting glycaemia was evaluated in our study, and was not found to be statistically significant by sex or age; in the most prevalent age-group with dry eye (56.6-67.4 year old), we did not have the longest time of diabetes, nor the highest glycaemia. However, some studies report that diabetic keratoconjunctivitis sicca is more often found in diabetics with poorer glycemic control, and that dry eye syndrome occurs more often in the hyperglycemia phase, due to the high extracellular fluid osmolarity that disturbs tear production. ${ }^{(13,20,28,29)}$

We also analyzed comorbidities and use of medication in these patients. The most prevalent was hypertension (56.9\%), and $84.48 \%$ used at least one medication. The most commonly used medication was oral hypoglycemic agents (98\%) followed by angiotensin converting enzyme inhibitors (56.0\%). It is controversial that some comorbidities can be a risk factor to dry eye syndrome. Schaumberg found that patients with hypertension and using drugs to treat hypertension and antidepressants had a higher prevalence of dry eye ${ }^{(21)}$. Moss, in 2000, found that allergies, hypertension and use of antihistamines and diuretics were an important risk factor to dry eye. ${ }^{(7)}$ However, the same author in 2004 did not find any relation between a lot of comorbidities with dry eye, like arterial hypertension, cardiovascular disease, thyroid disease, smoking, stroke, allergies or use of antidepressants; diuretics and antihistamines were shown to be relevant risk factors; use of angiotensin converting enzyme inhibitor might be a protection factor $^{(15)}$.

Ocular disease was present in $48.7 \%$ of respondents. The most common was diabetic retinopathy (DR) (19\%). This evidence is related to other research that shows a greater incidence of DR in these patients. ${ }^{(20)}$ Previous lens surgery was present in $48.3 \%$ of patients; Moss reported no evidence of a relationship with other ocular diseases such as cataract, lens surgery or maculopathy with dry eye syndrome, ${ }^{(7)}$ although other studies show that lens surgery can cause dry eye symptoms. ${ }^{(30)}$

Eye drops were used by 19 of the 58 patients, and 14 of these used lubricants (24\%). Kaiserman verified that $20.6 \%$ of diabetics with dry eye used lubricants, which is a similar rate, ${ }^{(20)}$ and shows that some patients have been previously diagnosed with dry eye.

Limitations of our research were that it was mainly a descriptive study, which impairs statistical measurements, and that diabetic patient had other comorbidities that could be an independent risk factor to dry eye, although this is controversial. ${ }^{(15)}$

\section{ConCLUSION}

A better consensus in dry eye diagnosis should be reached, due to the poor correspondence between symptoms and objective tests for dry eye disease. There is a lack of epidemiological profile studies about diabetic symptomatic dry eye. Further research needs to be done to establish a real etiologic relationship between diabetes and dry eye, and its correlation to other risk factors. In spite of these limitations, we have strong evidence of this relationship, and in clinical practice, examination for dry eye should be part of the assessment of diabetic disease.

\section{ReFERENCES}

1. Writing Team for the Diabetes Control and Complications Trial/Epidemiology of Diabetes Interventions and Complications Research Group. Effect of intensive therapy on the microvascular complications of type 1 diabetes mellitus. JAMA 2002;287:2563-9.

2. Harrison TR: Diabetes Mellitus. In Harrison Principle of Internal Medicine 15th edition. Branwald E, Fauci S, Kasper D, Hauser LS, L Longo D, Jameson JL, editors. USA, Mc GrowHill; 2001. p. 2121.

3. Ding J, Sullivan DA. Aging and dry eye disease. Exp Gerontol. $2012 ; 47(7)$ :483-90. Review.

4. Riordan-Eva , Asbury T, Whitcher JP: Vaughan and Asbury's general ophthalmology. 16th ed. USA, McGraw-Hill Medical; 2003:308-310.

5. Caffrey BE, Richter D, Simpson T, et al. The Canadian dry eye epidemiology study. In: Sullivan DA, et al, ed. Lacrimal gland, tear film and dry eye syndromes 2. New York: Plenum Press; 1998. p.805-6.

6. Shimmura S, Shimazaki J, Tsubota K. Results of a populationbased questionnaire on the symptoms and lifestyles associated with dry eyes. Cornea 1999;18(4):408-11.

7. Moss SE, Klein R, Klein BE. Prevalence of and risk factors for dry eye syndrome. Arch Ophthalmol. 2000;118(9):1264-8.

8. Schein OD, Munoz B, Tielsch JM, Bandeen-Roche K, West S. Prevalence of dry eye among the elderly. Am J Ophthalmology 1997;124(6):723-8.

9. Brewitt H, Sistani F. Dry eye disease: the scale of the problem. Surv Ophthalmol. 2001 Mar;45 Suppl 2:S199-202. Review.

10. Goebbels M. Tear secretion and tear film function in insulin dependent diabetics. Br J Ophthalmol. 2000;84(1):19 -21.

11. Fujishima H, Shimazaki J, Yagi Y, Tsubota K. Improvement of corneal sensation and tear dynamics in diabetic patients by oral aldose reductase inhibitor, ONO-2235: aprelimina ry study. Cornea. 1996; 15(4):368-72. 
12. Jin J, Chen LH, Liu XL, Jin GS, Lou SX, Fang FN. Tear film function in non insulin dependent diabetics. Zhonghua Yan $\mathrm{Ke}$ Za Zhi. 2003;39(1):10-3.

13. Seifart U, Strempel I. The dry eye syndrome and diabetes mellitus. Ophthalmologe. 1994;91(2):235-9.

14. Sendecka M, Baryluk A, Polz-Dacewicz M. [Prevalence of and risk factors for dry eye syndrome]. Przegl Epidemiol. 2004, 58(1):227-33. Polish.

15. Moss SE, Klein R, Klein BE. Incidence of dry eye in an older population. Arch Ophthalmol. 2004; 122(3):369-73.

16. Jain S: Dry eyes in diabetes. Diabetes Care 1998, 21(8):13641382.

17. Manaviat MR, Rashidi M, Afkhami-Ardekani M, Shoja MR. Prevalence of dry eye syndrome and diabetic retinopathy in type 2 diabetic patients. BMC Ophthalmol. 2008;8:10. doi: 10.1186/ 1471-2415-8-10.

18. American Academy of Ophthalmology: Basic and Clinical Science Course Section 7 2002-2003: Orbit, eyelids, and lacrimal system. American Academy of Ophthalmology ; 2002. p. 244-5. (Basic \& Clinical Science Course)

19. Management and therapy of dry eye disease: report of the Management and Therapy Subcommittee of the International Dry Eye WorkShop (2007). Ocul Surf. 2007;5(2):163-78. Review.

20. Kaiserman I, Kaiserman N, Nakar S, Vinker S. Dry eye in diabetic patients. Am J Ophthalmol. 2005;139(3):498-503.

21. Schaumberg DA, Dana R, Buring JE, Sullivan DA. Prevalence of dry eye disease among US men: estimates from the Physicians' Health Studies. Arch Ophthalmol. 2009;127(6):763-8.

22. Korb DR, Herman JP, Finnemore VM, Exford JM, Blackie CA. An evaluation of the efficacy of fluorescein, rose bengal, lissamine green, and a new dye mixture for ocular surface staining. Eye Contact Lens. 2008;34(1):61-4.

23. Lee AJ, Lee J, Saw SM, Gazzard G, Koh D, Widjaja D, Tan DT. Prevalence and risk factors associated with dry eye symptoms: a population based study in Indonesia. $\mathrm{Br} \mathrm{J}$ Ophthalmol. 2002;86(12):1347-51. Review.
24. Sullivan BD, Evans JE, Dana MR, Sullivan DA. Influence of aging on the polar and neutral lipid profiles in human meibomian gland secretions. Arch Ophthalmol. 2006;124(9):1286-92

25. Liu NN, Liu L, Li J, Sun YZ. Prevalence of and risk factors for dry eye symptom in mainland china: a systematic review and metaanalysis. J Ophthalmol. 2014;2014 748654. doi: 10.1155/2014/ 748654. Epub 2014 Oct 15. Review.

26. Cavalli-Sforza LL. Genes, povos e línguas. São Paulo: Companhia das Letras; 2003.

27. Instituto Brasileiro de Geografia e Estatística ( IBGE). Censo Demográfico 2010 - Resultados do universo. [citado 2015 Out 24]. Disponível em: http://www.ibge.gov.br

28. Nepp J1, Abela C, Polzer I, Derbolav A, Wedrich A. Is there a correlation between the severity of diabetic retinopathy and keratoconjunctivitis sicca? Cornea. 2000;19(4):487-91.

29. Binder A, Maddison PJ, Skinner P, Kurtz A, Isenberg DA. Sjögren's syndrome: association with type-1 diabetes mellitus. $\mathrm{Br} \mathrm{J}$ Rheumatol. 1989;28(6):518-20.

30. Yao K, Bao Y, Ye J, Lu Y, Bi H, Tang X, Zhao Y, Zhang J, Yang J. Efficacy of $1 \%$ carboxymethylcellulose sodium for treating dry eye after phacoemulsification: results from a multicenter, openlabel, randomized, controlled study. BMC Ophthalmo

\section{Corresponding author:}

Marina Moura Rezende

Prefeito Abdon Arroxelas,219, apto 303

Ponta Verde, Maceió - AL, Brasil

Telefone: (82)9301-1132

E- mail: dra.marinaribeiro@gmail.com 